\title{
Enhancing Social-Environmental- Economical Systemic Vision: Applying OLCA in a NGO
}

\author{
José Manuel Gil-Valle and Juan Pablo Chargoy-Amador
}

\begin{abstract}
Emmaüs International a non-governmental organization (NGO) in the social and environmental sector had practiced, since its foundation - now more than 60 years - the recuperation of objects that others consider as waste. This activity had allowed collecting the funds to help the needy giving them the means to find their dignity that society had taken. Nowadays, the modes had changed, and these recovery activities had made of Emmaüs movement a well-known actor against the noncontrolled waste "an environmental actor" working in the reuse and recycling. Given its environmental focus, Emmaüs has interest in assessing the environmental impacts of its own activities throughout the whole value chain. Therefore, an organizational life cycle assessment (O-LCA) study had been conducted as a test in one Emmaüs community. The study was realized in the framework of the road testing of the UNEP/SETAC Guidance on Organizational Life Cycle Assessment. It is important to mention that the avoided burdens assessment is not part of the O-LCA method.
\end{abstract}

\section{Introduction}

The Emmaüs community Etagnières, as a non-governmental organization (NGO) in the social and environmental sector, is interested in assessing the environmental impacts of its own activities throughout the whole value chain. Therefore, an organizational life cycle assessment (O-LCA) study was conducted. The study was performed in the framework of the road testing of the UNEP/SETAC Guidance on Organizational Life Cycle Assessment [1, 2].

Emmaüs' goals are of analytical, managerial and societal nature. The O-LCA study offer insights in internal operations as well as in other steps of the value chain, with a focus on wood board recycling. The results allow identifying environmental

J. M. Gil-Valle (ه)

LCI Member (Private advisor), Etagnières, Switzerland

J. P. Chargoy-Amador

Center for Life Cycle Assessment and Sustainable Design (CADIS), Life Cycle Management

Director, Mexico City, Mexico

Z. S. Klos et al. (eds.), Towards a Sustainable Future - Life Cycle Management, 
hotspots and set a reference for performance tracking over time. In a parallel study, the avoided burdens originated by the nature of the organization (recycling) will be analysed and compared with the results of the O-LCA. It is important to mention that the avoided burdens assessment is not part of O-LCA.

The study delivers the basis for environmental communications with stakeholders and reporting and allows showing environmental awareness with marketing purposes.

In general, the results of the study were analysed as an outcome of the roadtesting phase of the Flagship initiative "LCA of Organizations" in the framework of the UNEP/SETAC Life Cycle Initiative and are publically available.

\section{Materials and Methods}

Using life cycle assessment (LCA) to quantify the environmental performance of products has become a global trend, since a comprehensive evaluation is achieved, considering all stages of the life cycle, as well as the different environmental problems, including the carbon footprint. The advantages and potential of LCA are not limited to a product application, and although the methodology was originally developed with this approach, its application at the organizational level is possible and is increasingly relevant.

The technical specification ISO/TS 14072:2014 Environmental management Life cycle assessment - Requirements and guidelines for organizational life cycle assessment [3] describes the application of LCA with an organizational approach. In this way, it extends the application of ISO 14040 [4] and ISO 14044 [5] for all the activities of the organization, which means that the system evaluated covers the life cycle of the different products and operations within the same study.

O-LCA consists of the collection and evaluation of inputs, outputs and potential environmental impacts of the activities associated with an organization considered as a whole or portions of it, adopting a life cycle perspective.

ISO/TS 14072: 2014 provides details on:

- The application of LCA principles and methodology to organizations.

- The benefits that LCA can provide to the organization, using the methodology at the organizational level such as defining environmental aspects in the Environmental Management Systems ISO 14001: 2015, quantifying the environmental impact in an integral way and helping in strategic decision-making and prioritizing the actions that must be carried out to reduce the environmental impact of the organization.

O-LCA quantifies potential environmental impacts through a reporting flow, which is equivalent to the functional unit in a traditional LCA and is used as a reference. The system limits are defined by one of the following consolidation methodologies: 
- Operational control

- Financial control

- Participation in shares (percentage of ownership)

In addition, O-LCA proposes two ways to perform data collection: the bottomup approach and the top-down approach. In the first, the impact of the organization will be calculated with the sum of the LCA of each of the products it manufactures. This implies a collection of data broken down by product, which can be extremely complex for organizations with large portfolios. In the case of the top-down approach, the inputs and outputs of the system can be collected as a whole, by production plant (site) or even by business group. This approach eases the collection of information and allows disaggregation of the results according to the information needs of the organization.

O-LCA can be used as an input for environmental communication, especially for monitoring the environmental performance of the organization over time (performance tracking).

\section{Results}

\subsection{Goal and Scope}

The assessed organization was a local Emmaüs community, located in Etagnières, Switzerland, during 1 year from January 2015 to December 2015. The reporting flow was the annual sales expressed in mass $(\mathrm{kg})$.

The system boundary considered a cradle-to-gate approach for the inputs and outputs necessary for each of the activities included, extended by considering the transport of sold goods by the costumers. The production and first use of products are not considered, as well as the use and end of life of the sold recycled materials. The activities considered are categorized into indirect upstream activities and direct activities. Supporting activities like the organization's buildings and employee commuting were considered. System boundary is depicted in Fig. 1.

\subsection{Inventory Analysis}

A top-down screening approach was used as first approximation to obtain a basis for future studies. Transport data is collected with higher granularity and disaggregated into trucks transport, direct donor transport and customer transport.

Energy data was disaggregated in energy production on site and electrical - solar.

Both generic and specific data were used. The source is on-site, from literature, statistics and databases. A data quality scheme was used with the following criteria: 


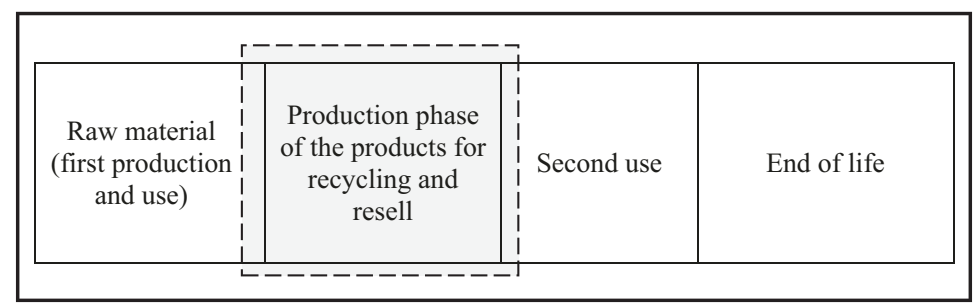

Fig. 1 Emmaüs community system boundary

Table 1 Impact assessment results

\begin{tabular}{l|l|l|l}
\hline Damage (Pt) & Direct activities & Indirect activities & Total \\
\hline Climate change, human health & 2294 & 11,594 & 13,888 \\
\hline Ozone depletion & 0,000 & 0,004 & 0,004 \\
\hline Human toxicity & 0,073 & 1513 & 1586 \\
\hline Photochemical oxidant formation & 0,000 & 0,000 & 0,000 \\
\hline Particulate matter formation & 0,543 & 1704 & 2247 \\
\hline Ionizing radiation & 0,000 & 0,145 & 0,145 \\
\hline Climate change, ecosystems & 1451 & 7336 & 8788 \\
\hline Terrestrial acidification & 0,004 & 0,009 & 0,014 \\
\hline Freshwater eutrophication & 0,000 & 0,008 & 0,008 \\
\hline Terrestrial ecotoxicity & 0,003 & 0,021 & 0,025 \\
\hline Freshwater ecotoxicity & 0,000 & 0,042 & 0,042 \\
\hline Marine ecotoxicity & 0,000 & 0,008 & 0,008 \\
\hline Agricultural land occupation & 0,000 & 0,493 & 0,494 \\
\hline Urban land occupation & 0,000 & 0,095 & 0,095 \\
\hline Natural land transformation & 0,000 & 0,409 & 0,409 \\
\hline Metal depletion & 0,003 & 0,950 & 0,953 \\
\hline Fossil depletion & 0,003 & 11,615 & 11,618 \\
\hline Total & 4378 & 35,953 & 40,331 \\
\hline
\end{tabular}

reliability, completeness, temporal correlations, geographical correlation and further technological correlation.

\subsection{Impact Assessment}

The impact assessment method ReCiPe Endpoint (H) [6] was applied. The main impacts have been detected in the categories climate change, human health and ecosystem followed by fossil depletion and particle matter formation. The impacts related to the transportation of sold materials represent an overall contribution of $41 \%$. Impact assessment results are depicted in Table 1. 


\section{Discussion}

The assessment with the ReCiPe Endpoint method allowed identifying environmental hotspots in the impact categories climate change, human health and ecosystem, followed by fossil depletion and particle matter formation. Electricity production, organization's buildings and transport of purchased goods are found being relevant activities. Actions to reduce transport-related impacts, such as selling points next to potential customers and online sales, are recommended.

The main limitations of the study consist in the exclusion of certain capital goods such as trucks and the boiler. The same applies for cleaning products, medicines, gardening products and personal care products that could be analysed in the future because of the potential effects of micropollutants. Facilities as kitchen, green and gardening areas were not included since they were already targeted in the framework of our food recuperation programme. Moreover, the use and end-of-life phase of the sold recycled products are not considered in this study.

Through O-LCA study, the hotspots could be detected. This could help improving the image of the community as a main actor regarding environmental activities. Emmaüs' study was a pilot and serves as example for other Emmaüs communities around the world. As first application in an NGO, Emmaüs' O-LCA experience has the great potential of being a landmark for environmental assessment activities among charitable organization.

\section{Conclusions}

O-LCA is useful in detection of the main environmental impact categories and their contribution concerning indirect and direct activities. A performance tracking of the mentioned activities could be established from this study on.

The study delivers the basis for the communication of "Sustainable Development Issues" with stakeholders (customer, services providers and partners) and reporting.

A basic model to apply the O-LCA methodology had been established in an Emmaüs recycling community that could be applied in other Emmaüs communities in the future.

The tools developed to apply this methodology were designed with the aim of supporting recycling communities around the world and the whole Emmaüs organization to evaluate and to reduce their environmental impacts in their own communities but also in the regions where they operate, thus positively affecting local development.

Further applications of the study are being considered. First, the data collected could be used in the future as environmental data basis for a formal Environmental Management System (EMS). Second, the Emmaüs community could serve as a pilot project as O-LCA is concerned. In fact, further recycling communities 
worldwide could apply the methodology in the future, thus enabling an assessment of the whole organization or a broader part of it.

From this perspective, Emmaüs is a first mover in the NGO sector.

\section{References}

1. UN environment. (2017). Road testing organizational life cycle assessment around the world. Life Cycle Initiative.

2. Guide on Organizational Life Cycle Assessment (2015, English, 148 pages).

3. ISO/TS 14072:2014 Environmental management - Life cycle assessment - Requirements and guidelines for organizational life cycle assessment.

4. ISO 14040:2006 Environmental management - Life cycle assessment - Principles and framework.

5. ISO 14044:2006 Environmental management - Life cycle assessment - Requirements and guidelines.

6. Huijbregts, M., Steinmann, Z., Elshout, P., Stam, G., Verones, F., Vieira, M., Zijp, M., Hollander, A., \& van Zelm, R. (2017). ReCiPe2016: A harmonised life cycle impact assessment method at midpoint and endpoint level. The International Journal of Life Cycle Assessment, 22(2), 138-147. https://doi.org/10.1007/s11367-016-1246-y

Open Access This chapter is licensed under the terms of the Creative Commons Attribution 4.0 International License (http://creativecommons.org/licenses/by/4.0/), which permits use, sharing, adaptation, distribution and reproduction in any medium or format, as long as you give appropriate credit to the original author(s) and the source, provide a link to the Creative Commons license and indicate if changes were made.

The images or other third party material in this chapter are included in the chapter's Creative Commons license, unless indicated otherwise in a credit line to the material. If material is not included in the chapter's Creative Commons license and your intended use is not permitted by statutory regulation or exceeds the permitted use, you will need to obtain permission directly from the copyright holder.

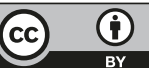

